\title{
INFORMATION TECHNOLOGY STRATEGIES FOR SMALL BUSINESSES
}

\author{
Mysore Ramaswamy, Southern University, Baton Rouge, LA, mysore@acm.org
}

\begin{abstract}
Information Technology (IT) provides ready to use, end-to-end solutions and allow small businesses to focus on their core businesses. Recent innovations in IT have positively impacted businesses. With the emergence of web services, the convergence of telecom and computing is finally reaching maturity in a unified platform for doing business in the $21^{s t}$ century. Business enterprises have invested heavily in information technology and the benefits have been well documented. However there is still a dearth in the current literature that analyzes how this digital technology can help small businesses in such areas as business process reengineering and data analytics. This paper seeks to fill this gap and proposes a framework that helps in choosing the appropriate IT strategy. It is essential that business processes are identified based on their cost, complexity, and criticality and then reengineered and automated based on analyzing the domain specific data.
\end{abstract}

Keywords: IT Strategy, Business Data Analytics, Business Process Reengineering, Small Businesses

\section{INTRODUCTION}

Information Technology provides ready to use, end-to-end solutions and allow small businesses to focus on their core business. Recent innovations in digital technology can play a significant role in spurring the growth of small businesses. Small and medium scale enterprises account for more than 90 percent enterprises in most OECD (Organization for Economic Cooperation and Development) nations and provide about 80 percent of economic growth (Scupola, 2009). Significant research shows that these businesses contribute to economic growth in multiple ways. Their presence in an economy leads to more competitive large enterprises that can outsource some of their activities to smaller firms. Compared to their relatively small sizes, they create more jobs than large firms (Passerini, 2012). Smaller size is an advantage, particularly in terms of the ability to anticipate and respond to changes and achieve a deeper and closer interaction with the customers. Some small businesses lack a technology strategy mainly due to the business owner's disengagement in technology and its role in business (Mulvey, 2014). This problem compounds to a failure to correctly align a company's resources, including its IT, with strategic objectives of the organization. The consequences of of a missing IT strategy can be considerable, often resulting in lost opportunities to use technology as a catalyst to achieve critical business performance improvements.

Information is an important asset that gives small businesses a competitive advantage in the new economy. Information access plays a critical role in the informed decision making process, making it easy for these businesses to make good competitive decisions (Modimogale, 2011). The ability of small businesses to survive in an increasingly competitive global environment is largely predicated upon their capacity to leverage information as a resource. In today's fierce competitive environment, small businesses need to be highly responsive and adaptive to demands of customers, actions of competitors, and changes in economic conditions (Rashaniphon, 2011). Data analytics can be as useful to small businesses by identifying those business processes that are capable of exploiting the new innovations in that area.

This paper is organized as follows. First, we briefly describe the current scenario pertaining to small businesses. The impact of IT on small businesses is discussed next. The next section proposes a framework that will help adopt the appropriate IT strategy for small businesses. Concluding remarks form the last section.

SMALL BUSINESSES 


\section{Issues in Information Systems}

Volume 20, Issue 2, pp. 216-225, 2019

Even though the economic importance of small and medium scale enterprises has been known, they were considered comparatively unimportant during the great Internet boom during the 1990s and early 2000s (Passerini, 2012). Use of broadband information technology required extensive investment in technological assets and a long term access to capital. Such capital requirements were not available to small businesses. Today small businesses can compete and excel due to continual improvements in Internet technology as well as breakthroughs in cloud computing and mobile connectivity.

Access to capital and an established brand name are the main advantages of large organizations. One of the greatest advantages small businesses have is flexibility. Many small businesses have a single owner who is free to change policies, and technologies (Sadowski, 2002). For example, the owner of a small grocery store can decide to use broadband to create an automatic reorder system with suppliers. Small businesses can offer new services and change internal processes without having to clear a multitude of committees that would exist in a large organization. Cloud computing, and open source software have brought down the investment requirements and costs. This has resulted in the availability of broadband technologies to small businesses to streamline business processes, grow the customer base, and enlarge existing offerings.

According to Kirchoff's typology (Kim, 2004), small firms can be classified based on two dimensions: innovation and growth as shown in Appendix I. Core firms represent where innovation and growth are low, whereas Glamorous firms have innovation and growth at a high level. Constrained companies have low growth potential but high innovation potential. Ambitious firms have high growth potential but low innovation potential. This paper mostly focuses on Core firms. Mills (2015) classifies small businesses based on types of firms - whether they are sole proprietorships, B2B, etc. - as indicated in Appendix II. Most of the Core small businesses are either sole proprietorships, or local businesses serving consumers and other local businesses. Lower costs of Information Technology (IT) deployment, mobility advantages supported by broadband, and an IT services support system (now directly available as-a-service) can help the more IT conservative small firms (such as 'core' as indicated in Appendix I) to transition to the new mobile apps (Passerini, 2012).

There is a lack of knowledge about the potential benefits of information technology and strategies to support small businesses in achieving their business objectives. Small businesses face the challenge that generally they are owner managed and the owner makes all or most of the decisions about the business (Fillis, 2004; Spencer, 2006). Unfortunately, owner-manager's limitations become limitations of the business. Information technology needs to be considered a key player for the small business in reaching its goals. As information technology is perceived to be expensive by small businesses, they often do not budget for it. The other problem with regard to the cost of IT is that small businesses may invest in unnecessarily big solutions due to sales pitches, hype of specific products or market patterns without considering their real need [Grandon, 2004). Technology is constantly evolving which raises two issues. On the one hand the small businesses need to monitor the kind of technologies that their clients are using and try to make sure that they are ready to serve them. On the other hand, the small businesses s do not need to change every time there is a change in technology as this depends upon the focus area of the small businesses. The competitiveness of a small business depends on the way in which IT is used to support business processes.

\section{SMALL BUSINESSES AND INFORMATION TECHNOLOGY}

Small businesses can leverage information technology (IT) in two different ways. One way is to enhance operational support and transaction processing activities. Small businesses adopt and use simple IT innovations without any form of planned strategy to integrate other aspects of business (Qureshil, 2009). In this approach, any form of IT-based competitive advantage is accidental rather than planned. The second way is typically taken to use IT to improve interaction and relationship with customers. A majority of small businesses depend on a small number of customers who purchase large amounts of goods and services. These major customers influence the price of goods and services provided by small businesses. Close relationships among small businesses and customers enable these businesses to respond quickly to any change in customer requirements. 


\section{Issues in Information Systems}

Volume 20, Issue 2, pp. 216-225, 2019

Levy (2001) has proposed an analytical framework that incorporates both forms of strategic focus. In this FocusDominance Model (Appendix III), customer dominance is compared with strategic focus. This framework provides four different strategies to IT adoption. The "Efficiency" quadrant consists of small businesses that exploit simple systems such as word processing and spreadsheets. The "Coordination" quadrant consists of small businesses that have a need to increases market share and their customer base. The "Collaboration" quadrant indicates those small businesses that attempt to incorporate emerging technologies to manage relationships with major customers. The "Innovation:" quadrant consists of those businesses that actively seek to adopt new IT innovations to achieve competitive advantage.

In a follow-up study, Levy (2002) investigated 43 small businesses to observe their positions in the FocusDominance Model. The results revealed that most of the small businesses make only one move, from "efficiency" to "coordination" or from "efficiency' to "collaboration." Small businesses taking either one of these paths tend to avoid losing control and stay within their current markets. It was also observed that only 17 out of the 43 small businesses wanted to move to the "innovation" quadrant perhaps due to environment scan that indicated possible business growth.

Small businesses can leverage techniques and tools that have become increasingly available as open source software such as 'Alfresco' software for content management (Passerini, 2012). Along with the traditional knowledge management processes that include acquisition/creation, storage and retrieval, dissemination and application, SMEs benefit from various size based advantages. For example, in the area of knowledge storage and retrieval, the proximity of project teams to the company owner enables quicker and more frequent transactions compared to large organizations.

Small businesses are often intimidated by the cost and complexity of handling large amounts of digital information. In the past, companies seeking to tap into big data needed to purchase expensive hardware and software, hire consultants and invest huge amounts of time in analytics. But trends such as cloud computing, open source software, and software as a service have changed all that (Simon, 2013). Data analytical strategies can help small businesses, whose marketing budgets are limited; employ better web design and marketing concepts. Today, web designers and marketers have access to a wealth of information which makes for useful intelligence with proper application. It is important to focus on critical data required for the analytics process. In the first stage, data is filtered to keep only what is relevant for the business (Davenport, 2006; Davenport, 2007). Next, the particular metrics which will draw out people from the general pool who are likely to become customers is identified. In the third stage, web and data analytical tools are used to track Internet marketing campaigns and measure results. Lastly, the available data is analyzed to derive meaningful interpretations and structures that can inform both online marketing campaigns and design strategies to result in better customer management.

Data intelligence can be applied to strengthen search engine optimization (SEO) strategies and to raise customer engagement with the business, which is also important for effective web design (Smith, 2010). It gives small business more cost efficient and effective tools and information to track online marketing achievements and give more consumer targeted strategies. The online environment gives small businesses boundless room for expansion for their reach and visibility. Big data can be used to draw out customer intelligence for more optimal design and marketing strategies (Dowson, 2015; Howso, 2008). Some of the ways through which small businesses can concentrate on strategies which will enable them to reach a bigger audience without sacrificing the quality of engagement are listed below:

- Building a website to leverage the Internet's ability to broadcast your business to a geographically limitless audience,

- Leverage the knowledge and skills of web design/development experts to ensure your business website is able to offer the best user experience including better online viewing and navigation for site visitors,

- Apply data analytics to take stock of different mobile devices used by your potential audiences and ensure that your website design effectively renders on all these devices. It should fit their viewing behavior and be optimized for as many mobile platforms as possible,

- Use social media data and search engine optimization (SEO) metrics to grow your social media assets which will increase your business exposure in organic search and social media networks (Davenport, 2007; Wailgum, 2009). 


\section{Issues in Information Systems \\ Volume 20, Issue 2, pp. 216-225, 2019}

Customer preferences are constantly changing, and data analytics provides a reliable tool to collect and process this information on consumer behavior and buying habits. Big data gives small businesses measurable metrics and intelligence which can improve the relevance of your site and content to your target audience. This is done through the use of predictive models like audience segmentation which can monitor your customers' buying habits to separate old customers from new, repeat customers from single-purchase ones, among others. Listed below ae some of the techniques that can be adopted:

- Customers are grouped as per their buying behavior and preferences, and the new segments are used to create more targeted messages

- Social data intelligence can be used to understand how and how much consumers are engaging with the business/brand on social platforms

- Intelligent algorithms and tools are applied to big data to give better customer insights and deliver targeted ads to every consumer

Customer data intelligence empowers small business owners by giving them more meaningful data to analyze customer behavior and business performance. Objective and valuable data thus collected from internal and external resources can then help drive business growth, and help small businesses direct their limited marketing resources towards strategies that will result in the highest conversions, engagement and sales. Passerini (2012) in her case study of "Transport Designs" analyzes how a firm that used computers only for payroll and scheduling done on subjective guesswork evolved into a company that uses wireless Ethernet to transfer draft drawings from the design office's computer to the factory floor's computer.

\section{FRAMEWORK FOR ADOPTION OF AN APPROPRIATE IT STRATEGY}

Although technology can create new or modified business practices at a rapid rate, successful adoption of new best practices must stand up to market forces. Technology and the marketplace are continually reshaping business activities and as a consequence, business strategies. An organization must continually work towards an alignment that fits into the organization's business strategy and IT strategy. This alignment should improve the likelihood that new initiatives are explicitly linked to areas that are critical to successful business performance, provide a source of competitive advantage. The role of IT should be that of a strategic enabler for competitive success, rather than just an operational supporter.

Business process reengineering (BPR) began as a private sector technique to help organizations to fundamentally rethink how they do their work in order to dramatically improve customer service, cut operational costs, and become more competitive (Bogdanoiu, 2014; Dowson, 2015). A key stimulus for reengineering has been the continuing development and deployment of sophisticated information systems and networks. BPR involves changes in structures and in processes within the business environment.

Redesign, retooling, and re-orchestrating form the key components of BPR that are essential for an organization to focus on the outcome that it needs to achieve. The entire technological, human, and organizational dimensions may be changed in BPR. Information technology plays a major role in business process reengineering as it provides office automation, it allows the business to be conducted in different locations, provides flexibility in manufacturing, permits quicker delivery to customers and supports rapid and paperless transactions (Bogdanoiu, 2014; Wu, 2005).

The BPR technique implements organizational change based on rapid change, employee empowerment, and training and support by information technology. In order to implement BPR to an enterprise, the following key actions need to take place:

- Selection of the strategic processes for redesign,

- Simplify new processes - minimize steps - optimize efficiency - modeling,

- Organize a team of employees for each process,

- Organize the workflow - document transfer and control,

- Assign responsibilities and roles for each process,

- Automate processes using information technology,

- Train the process team to efficiently operate the new process, 


\section{Issues in Information Systems \\ Volume 20, Issue 2, pp. 216-225, 2019}

- Introduce the redesigned process into the new organizational structure.

Applying BPR techniques to small businesses differ substantially from the way large enterprises deal with this issue. BPR concept requires an organization to have a strategy and then set business objective to achieve that strategy. In order to achieve the objective effectively, organization can apply BPR concepts to put the right processes in place (Rashaniphon, 2011; Wailgum, 2009). However, in the case of many small businesses, this classical approach may not be workable. Most of the successful people in small businesses are hands on persons and most likely they do not even bother about the word 'strategy', especially in the business environment of developing countries. It is more effective to try out hands on approach to make changes quickly. They are only looking for short term objectives.

Here are some guidelines that are especially relevant to small businesses (Mansar, 2007):

- Read the market for your business clearly by SWOT (Strengths, Weaknesses, Opportunities, and Threats)

analysis,

- Develop a strategy that optimizes cost, quality, time, and flexibility,

- Execute the developed strategy by strengthening the processes identified for reengineering and without interfering unnecessarily.

In this context, we can look at the results of two business surveys conducted by the U.S. Chamber of Commerce in January 2018. The first survey consisted of a national poll of 1,000 small businesses and 50 state-level polls of 100 small businesses. The second survey was a national consumer poll of more than 5,000 adults on the perceived benefits of digital platforms. Examining the use of digital platforms as a whole in the United States, the national survey finds that the use of digital platforms by small enterprises is ubiquitous:

- $84 \%$ of small enterprises are using at least one major digital platform to provide information to customers;

- $80 \%$ are using at least one major platform to show products and services, as well as to advertise;

- $79 \%$ are using digital tools to communicate with customers and suppliers, and

- $75 \%$ are using tech platforms for sales.

The national survey also revealed the importance of digital skills to managers in small businesses when hiring:

- $62 \%$ of small businesses surveyed stated that digital and social media skills are an important factor when hiring; a higher proportion reported this as a more important consideration than where a candidate attended school.

Even in a country with nearly universal Internet access, American businesses still view the cost of Internet services as a constraint to building an online presence: $55 \%$ reported that the cost of Internet and connectivity is a challenge. On the skills side, $57 \%$ of small businesses surveyed said that lack of familiarity with the digital tools available is a challenge. This finding suggests that even if a business obtains Internet access, it can be hard to know which tools to use. Recruiting skilled employees is a challenge for $61 \%$ of small businesses surveyed by the U.S. Chamber of Commerce in January 2018. Even when owners are able to successfully launch their businesses, they still have difficulty finding employees to expand operations.

One advantage to digitization is the ability to buy and sell across borders at a low cost. Of the small businesses surveyed, $27 \%$ reported selling goods or services to another country, a substantially higher proportion than the national proportion of U.S. firms that export. Yet, many small businesses are reluctant to trade internationally. When asked whether they think export activity is an important business activity, less than half of respondents stated that they believe that it is important to sell to other countries. Looking only at businesses that do not report exports, $43 \%$ said that they do not think there is demand for their goods and services in other countries, and $40 \%$ said that international exporting is too expensive.

In the first stage, existing business processes are examined. The number of processes is indeed very large as these pertain to upstream and downstream of the supply chain as well as operations related to the specific business. The gamut of these processes/interactions is also very diverse. The analysis is conducted along the three dimensions of complexity, criticality and cost. Socio-technical factors are considered in the second stage. Not only will this help towards transparency, but it will also make acceptance by constituents easier, Socio-technical factors pertain to exacerbated accountability dysfunctions that can occur as a consequence of automation. According to Bovens (2005) the major categories of dysfunctions are: Rule-obsession, and Proceduralism. Before manual procedures are automated, it has to be ensured that there are no problems due to such dysfunctions. 


\section{Issues in Information Systems}

Volume 20, Issue 2, pp. 216-225, 2019

Rule-obsession or Output-obsession refers to the focus on outcomes over process. 'Proceduralism' refers to increased emphasis on procedures to avoid responsibility and accountability. Strict adherence to procedures cam render the bureaucracy to lose the ability to balance procedures with corporate values. Relying heavily on encoded computer procedures can undermine the effectiveness of organizations.

Processes are restructured in the third stage. Automating legacy procedures that afforded plenty of opportunities for inefficiency will not yield results. At this stage, the results of data analytics are used to modify processes (Mills, 2015; Passerini, 2012). The main objective of restructuring various processes before transforming them into digital interactions is to improve the effectiveness as a system. When automated processes result in disintermediation, it is necessary that the relevant entities are on board with new procedures. After completion of the restructuring stage, we are ready for implementing in the fourth and final stage.

The degree of automation can vary across a wide range. Smith (2010) states a scale of nine degrees of automation starting from the first level where the computer offers no assistance to the ninth level where the computer decides everything. In between these extremes, there are several levels where a varying degree human-computer interaction occurs. The appropriate level of IT intervention depends on the particular interaction that has to be automated.

This framework also provides a means of evaluating extensive (if not comprehensive) series of business process transactions. Depending upon the value of the parameters of the given transaction, we are able to make inferences on the potential of that transaction for potential of IT intervention. This naturally opens up a wide arena of analysis, particularly for others who wish to specialize and focus specifically on the dynamics and characteristics of specific interactions where IT intervention is useful. This approach is effective since it focuses on specific critical processes of small businesses and renders overall improvement.

\section{CONCLUSION}

Small businesses can benefit from using techniques made available by emerging information technologies. New technologies are paving the way for new market creation. As a direct result of this, we have seen new small businesses emerging to cater niche markets as an alternative to impersonal commercial companies. Business process engineering and business data analytics have been used successfully in the corporate world. However, using these techniques for small businesses poses some problems. The basic building blocks of IT implementation consist of digitized versions of interactions among various business processes.

In this paper, we have presented a framework that can identify and categorize the different types of business processes/transactions. Restructuring these processes and then automating them in a systematic way as suggested in this paper affords a practical approach to leverage information technology. Monitoring the critical success factors will help in evaluating the success of these measures. Therefore, IT strategy for small businesses has to prioritize those critical activities that need to be automated first and then find optimal ways of restructuring those business processes. Future work in this area focuses on developing a comprehensive framework that will enable entrepreneurs and researchers to point out the potential priority areas that need to be automated first and also yield a realistic estimate of resources needed to achieve such transformation. In addition, such an approach will also help in giving a better insight into process restructuring.

\section{REFERENCES}

Bogdanoiu, C. (2014). Business Process Reengineering Method. Retrieved March, 14, 2018, from http://www.cesmaa.eu/ awards/ Best Student Paper_BogdanoiuCristiana.pdf

Bovens, M. (2005) "Public Accountability," in Ferlie, E. J. Lawrence, E. Lynn, and C. Pollitt (eds.), The Oxford Handbook of Public Management, Oxford University Press, pp. 182-208. 
Brooks, J. A., Treeter, A., and Vinson, S. (2017). Opportunities and Perils: Launching a Small Business. Proceedings of the $47^{\text {th }}$ SEDSI Conference, 424-431.

Davenport, T. H. (2006). Competing on Analytics. Harvard Business Review, 84(2), 98-107.

Davenport, T. H. and J. Harris. (2007). Competing on Analytics. Boston, MA: Harvard Business Review Press.

Dowson, J. (2015). Big Data Analytics and Business Intelligence for Better Customer Experience in Bmall Businesses. Retrieved April, 14, 2018, from http://www.datasciencecentral.com $/ \mathrm{m} / \mathrm{blogpost}$ ?id= 6448 $529 \% 3$ ABlogPost $\% 3 \mathrm{~A} 316525$.

Eckel, E. (2009). Ten Tech Mistakes Small Businesses Make. Retrieved April, 14, 2018, from https: //www.techrepublic.com/blog/10-things/10-tech-mistakes-small-businesses-make

Fillis, I. (2004). Factors Impacting on E-Business Adoption and Development in the Smaller Firm. International Journal of Entrepreneurial Behaviour and Research, 10(3), 178-191.

Grandon, E. E. (2004). Electronic Commerce Adoption: An Empirical Study of Small and Medium US Businesses. Information \& Management, 42(4), 197-216.

Howso, C. (2008). The Road to Making BI Available to Everyone. Information Week, Feb. 25.

Kamal, M. and Jackson, J. (2014). ICTs in Microenterprises: Does it Make a Difference? Proceedings of the Twentieth Americas Conference on Information Systems, 1-10.

Kim, H. M. (2004). Best Practices in E-Business Process Management: Extending a Re-engineering Framework. Business Process Management Journal, 10(1), 17-27.

Lefebvre, L. (2005). Exploring B-to-B E-Commerce Adoption Trajectories in Manufacturing SMEs. Technovation, 25(12), 1443-1456.

Levy, M., \& Powell, P. (1998). SME Flexibility and the Role of Information Systems. Journal of Small Business Economics, 11, 183-196.

Levy, M., Powell, P., \& Yetton, P. (2002). The Dynamics of SME Information Systems. Journal of Small Business Economics, 19, 341-354.

Levy, M., Powell, P., \& Yetton, P. (2001). SMEs: Aligning IS and the Strategic Context. Journal of Information Technology, 16(3), 133-144.

Mansar, S. L. (2007). Best Practices in Business Process Redesign: Use and Impact. Business Process Management Journal, (13, 2), 193-213.

Mefor, O. (2017). Why Small Businesses and Nonprofits Need an IT Strategy. Technical Library. 286. Retrieved May, 8, 2019, from http://scholarworks.gsu.edu/cistechlib/286

Mills, K. (2015). The Four Types of Small Businesses. Harvard Business Review (April).

Modimogale, L. (2011). The Role of ICT within Small and Medium Enterprises in Gauteng. Communications of the IBIMA, Vol. 2011, Article ID 369288, 12 pages.

Mulvey, D. S. (2014). Developing a Small Business IT Strategy. In Advanced Network Products. Retrieved March 21, 2019 from http://www.anp.net/blog/bid/386146/Developing-a-Small-Business-IT-Strtegy 
Passerini, K., A. Tarabishy, and K. Patten. (2012). Information Technology for Small Business. New York, NY: Springer.

Porter, M. (2001). Strategy and the Internet. Harvard Business Review, 79(3), 63-78.

Premkumar, G. (1999). Adoption of New Information Technologies in Rural Small Business. OMEGA International Journal of Management Science, 27(4), 467-484.

Qureshi, S., Kamal, M., and Wolcott, P. (2009). Information Technology Interventions for Growth and Competitiveness in Microenterprises. International Journal of E-Business Research, 5(1), 117-140.

Rashaniphon, S. (2011). Business Process Reengineering and Thai Small and Medium Enterprises. Proceedings of the International Conference on Management and Service Science, 8, 69-73.

Raymond, L. (1985). Organizational Characteristics and MIS Success in the context of Small Business. MIS Quarterly, 9(1), 37-52.

Rhoton, J. (2013). Cloud Computing. Lexington, KY: Recursive Press.

Sadowski, B. M. (2002). Strategic Use of the Internet by Small and Medium-Sized Companies: An Exploratory Study. Information Economics and Policy, 14(1), 75-93.

Scupola, A. (2009). SMEs' E-Commerce Adoption: Perspectives from Denmark and Australia, Journal of Enterprise Information Management, 22(1/2), 152-166.

Simon, P. (2013). Even Small Companies Can Tap Big Data if They Know Where to Look. Harvard Business Review, (December 16, 2013).

Smith, M. L. (2010) "Automating the Public Sector and Organizing Accountabilities," Communications of the Association for Information Systems, 26, Article 1.

Spencer, A. S. (2006). Schumpeter and New Technology Based Firms. International Enterprise Management Journal, 2, 145-156.

Wu, F. (2005). An Analysis of E-Business Adoption and Its Impact on Business Performance. Journal of the Academy of Marketing Science, 31(4), 425-447.

Zhu, K. (2002). E-Commerce Metrics for Net-Enhanced Organizations: Assessing the Value of E-Commerce to Firm Performance in the Manufacturing Sector. Information Systems Research, 13(30), 275-295. 
Appendix I. Kirchoff's Typology of Small Firms [Adapted from (Passerini, 2012)]

\begin{tabular}{|l|l|}
\hline $\begin{array}{l}\text { CONSTRAINED } \\
\text { Low Growth }\end{array}$ & $\begin{array}{l}\text { GLAMOROUS } \\
\text { High Innovation } \\
\text { High Growth }\end{array}$ \\
\hline CORE & \\
$\begin{array}{l}\text { Low Innovation } \\
\text { Low Growth }\end{array}$ & AMBITIOUS \\
& $\begin{array}{l}\text { Low Innovation } \\
\text { High Growth }\end{array}$ \\
\hline
\end{tabular}

Appendix II. Types of Small Businesses [Adapted from (Mills, 2015)]

\section{The Four Main Types of Small Businesses}

\begin{tabular}{|c|c|c|}
\hline TYPES OF FIRMS & NUMBER OF FIRMS* & DESCRIPTION \\
\hline $\begin{array}{l}\text { Non-Employee } \\
\text { Businesses }\end{array}$ & 23 million & Sole proprietorships \\
\hline Main Street & 4 million & $\begin{array}{l}\text { Local businesses serving consumers and } \\
\text { other local businesses }\end{array}$ \\
\hline Suppliers & 1 million & $\begin{array}{l}\text { Suppliers to other businesses (B2B) } \\
\text { in the traded sector }\end{array}$ \\
\hline High-Growth & 200,000 & Fast-growing, innovation-driven businesses \\
\hline
\end{tabular}




\section{Issues in Information Systems}

Volume 20, Issue 2, pp. 216-225, 2019

Appendix III. Focus-Dominance Model [Adapted from (Qureshi, 2009)]

Customer Dominance

\begin{tabular}{|l|l|}
\hline Low & Innovation \\
\hline High & Coordination \\
\hline Efficiency & \\
\hline Cost & Value Added \\
\hline
\end{tabular}

Strategic Focus 